\title{
The influence of coating color, heartwood and sapwood, on moisture content and growth of microorganisms on the surface during outdoor exposure of Norway spruce boards
}

\author{
Tinh Sjökvist $\mathbb{D}$, Åsa Blom
}

(C) The Author(s) 2019

\begin{abstract}
The use of wood contributes to the global transformation into a bio-based community. There are, however, challenges. The growth of mold, rot fungi, and algae on the coated surface is of major concern due to decreased aesthetic service life and shorter maintenance intervals. The colonization of a coated surface requires the presence of spores, nutrients, and a sufficient amount of water. This work studied the influence of using heartwood and sapwood on the moisture content (MC) and growth of microorganisms on the surface of coated Norway spruce boards [Picea abies (L.) Karst.]. The results revealed a relationship of heartwood samples having a lower MC and a lower or equal degree of biological growth on the coated surface than sapwood samples. The relationship was valid through a range of densities $\left(309-548 \mathrm{~kg} / \mathrm{m}^{3}\right)$ and two different coating systems based on either an alkyd or an acrylic resin. Furthermore, the choice of coating color (red compared to white) affected the MC as the red-colored samples had a lower MC, combined with no growth of microorganisms.
\end{abstract}

Keywords Mold, Fungi, Algae, Durability, Cladding

\section{Introduction}

The world's limited natural resources have increased the intentions of the society to transform into a biobased community. The use of wood from a renewable resource contributes to this goal. There is, however, a challenge since exterior wood, such as that used in

T. Sjökvist $(\bowtie)$, А. Blom

Department of Forestry and Wood Technology, Linnaeus

University, 35195 Växjö, Sweden

e-mail: tinh.sjokvist@lnu.se

Å. Blom

e-mail: asa.blom@lnu.se house claddings, is constantly attacked by different deteriorating factors, leading to decreased esthetic service life and shorter maintenance intervals. One initial deteriorating factor is the surface growth of fungus, mold, and algae. ${ }^{1}$ Low moisture content (MC) is crucial for preventing this phenomenon since a high MC enhances biological colonization. ${ }^{2}$ A coating is often used to protect the wood (for example, to reduce the water sorption rate).

Many studies have focused on the performance properties of different wood coatings. ${ }^{3-6}$ However, some have paid attentions to the properties of the underlying wood substrate. ${ }^{7-11}$ Different parts of the tree exhibit different properties. During the maturation of the tree, wood tissues transform from sapwood to heartwood after the cessation of wood nutrients following the death of living parenchyma cells and the closure of water paths by pit aspiration. ${ }^{12}$ Norway spruce [Picea abies (L.) Karst.] is a common species used for exterior coated house claddings. Studies have found that uncoated heartwood spruce absorbs less water than sapwood. ${ }^{13-15}$ Additionally, heartwood spruce has less growth of microorganisms on the surface than sapwood. $8,10,16$

In coated spruce boards, the heartwood substrate exhibits a similar trend with less growth of microorganisms on the surface. ${ }^{8}$ The organisms require three major conditions to colonize: the presence of spores, sufficient nutrients, and sufficient water. It is therefore very likely that one contributing mechanism behind less growth of microorganisms on the surface of coated spruce is the lower MC of heartwood compared to sapwood since a coating does not change the equilibrium water sorption levels and only affects the sorption rate. ${ }^{17}$ Depending on the properties of the coating, such as permeability properties, the coating surface will more or less adapt to the moisture level of the wood. Aureobasidium pullulans, one of the most significant mold species on coating surfaces, also goes beyond 
surface growth, to reach down to the wood by growing through the coating barrier. ${ }^{18}$ Sunlight radiation causes increased temperatures on a coated surface. Grüll et al. ${ }^{19}$ explained the lower MC of samples with darker coatings with the higher energy absorption from sunlight. Elevated temperatures could also decrease the growth of microorganisms on the surface.

Therefore, this paper's hypothesis is that the lower $\mathrm{MC}$ of heartwood spruce contributes to less growth of microorganisms on the surface. Furthermore, a darker coating color has a positive suppressing effect on the growth of microorganisms by a decrease in the MC.

The protective properties of a coating decrease through weathering degradation with corresponding brittleness and crack formations in the coating. ${ }^{19}$ Hence, the properties of the wood substrate will be emphasized with increased weathering. For example, coated sapwood spruce develops a similar cracking as uncoated sapwood spruce with increased weathering. Sapwood develops a greater number and length of cracks than heartwood spruce, and the measured difference is accentuated with increased weathering of the coating. 8

There are very few long-term studies concerning the $\mathrm{MC}$ variation of coated heartwood and sapwood spruce in aboveground outdoor exposure situations. The aim of this work is therefore to expand the knowledge about the relationship between MC and the growth of microorganisms on the surface of coated wood. The focus will be given to the influence of the heartwood and sapwood characteristics and of coating colors. The objective is to monitor the MC and growth of microorganisms on heartwood and sapwood spruce boards of differing densities, coating formulas, and colors, during approximately 5 years of outdoor exposure in southern Sweden.

\section{Materials and methods}

Logs of Norway spruce [P. abies (L.) Karst.] were selected from the area of Växjö in southern Sweden. The sapwood border of these logs was marked at the time of felling. After sawing, the planks were dried in an industrial kiln with a maximum temperature of $70^{\circ} \mathrm{C}$ until they reached a MC of approximately $17 \%$ as measured relative to oven-dry weight. After that, the dried materials were reduced to a board size of $20 \times 100 \times 375 \mathrm{~mm}$ (radial $\times$ tangential $\times$ longitudinal measurements). Wood material was vetted to be straight-grained with only sound knots and no cracks or resinous streaks. The boards were then divided into heartwood and sapwood for a total of 60 boards with an oven-dry density between 305 and $548 \mathrm{~kg} / \mathrm{m}^{3}$ and a growth ring width between 1 and $11 \mathrm{~mm}$ (Table 1). The oven-dry density of the samples was estimated from their stable mass and volume at $20^{\circ} \mathrm{C}$ and $65 \%$ relative humidity (RH), using an equilibrium moisture content (EMC) of 12\%, standard deviation
$($ stdev $)=0.5$. EMC is the state where the rate of water uptake and release in the wood are equal. The EMC was measured from the stable conditioned mass relative the stable oven-dry mass at an oven temperature of $103^{\circ} \mathrm{C}$ using uncoated spruce $(70$ pieces heartwood, 70 pieces sapwood) from the same wood material source with a density range of $313-489 \mathrm{~kg} / \mathrm{m}^{3}$ (mean $388 \mathrm{~kg} / \mathrm{m}^{3}$, stdev $=68 \mathrm{~kg} / \mathrm{m}^{3}$ ).

The samples were acclimatized in a climate chamber at $20^{\circ} \mathrm{C}$ and $65 \% \mathrm{RH}$ before the application of a coating. The application of the coating was on the bark side, side faces, and end grains. The pith sides of the boards were uncoated as house claddings normally have the backside of the board uncoated.

The Swedish Paint and Adhesives Association selected exterior coatings for house claddings based on either an alkyd or an acrylic resin. The manufacturer and specific formula of the coating systems were unknown to the researchers. However, this study intended to observe the effect of the wood substrate within each coating system. The selection of coating systems was to present different coatings rather than to compare them. The coating systems were white (NCS S0500) waterborne alkyd (A), white (NCS S0500) waterborne acrylic (B), and red (NCS S5040Y80R) waterborne acrylic (C). Coatings $B$ and $C$ had the same formula except for the pigmentation. In Sweden, exterior wood is frequently coated with the red color specified in this study. The color resembles a very popular traditional calcimine paint. The application of the coatings was made according to the manufacturer's recommendations regarding layers, thickness, and drying. The samples were dried between each layer, at $20^{\circ} \mathrm{C}$ and $65 \%$ relative humidity $(\mathrm{RH})$. The coating letter was the same as the sample letter (e.g., Sample B was treated with coating B).

The exposure of the samples was during the period of October 12, 2011-August 26, 2016, at the Swedish Infrastructure of Ecosystem Science (SITES), Asa field research station, $40 \mathrm{~km}$ north of Växjö, Sweden. Weather data were collected from a weather station at the test field, maintained by SITES (Fig. 1). The samples were exposed vertically on racks with a $45^{\circ}$ inclination to the south at approximately $60 \mathrm{~cm}$ above ground level (Fig. 2). Every other month, the mass of the samples was measured with an accuracy of $0.1 \mathrm{~g}$. The oven-dry mass was used to calculate the MC. The biological growth on the tangential plane of the coated surface was monitored every year according to a gradation similar to the standard EN ISO 4628-1, ${ }^{20}$ using grade $0-5$, where grade $0=$ no detectable defects/biological growth and grade $5=$ dense pattern of defects/biological growth (Fig. 3).

A one-way ANOVA was performed using the software program IBM SPSS version 24 to determine the average $\mathrm{MC}$ for each replicate and sample group. One sample consisted of five replicates. The average MC was calculated according to equation (1) where $n=$ the $n$th measurement of the replicate, 
Table 1: Density and growth ring width of the samples with the standard deviation listed in parentheses

\begin{tabular}{|c|c|c|c|c|c|c|c|}
\hline \multirow[t]{2}{*}{ Sample } & \multirow{2}{*}{$\begin{array}{c}\text { No } \\
\text { Replicates }\end{array}$} & \multicolumn{3}{|c|}{ Density $\left(\mathrm{kg} / \mathrm{m}^{3}\right)$} & \multicolumn{3}{|c|}{ Growth ring width (mm) } \\
\hline & & Average & Min & Max & Average & Min & Max \\
\hline \multicolumn{8}{|l|}{ Coating A } \\
\hline Heartwood & 10 & $382(54)$ & 324 & 488 & $6.5(3.0)$ & 2 & 11 \\
\hline Sapwood & 10 & $454(53)$ & 353 & 515 & $3.8(2.4)$ & 2 & 6 \\
\hline \multicolumn{8}{|l|}{ Coating B } \\
\hline Heartwood & 10 & $378(63)$ & 314 & 498 & $5.7(3.3)$ & 2 & 11 \\
\hline Sapwood & 10 & $443(100)$ & 309 & 548 & $3.4(2.2)$ & 1 & 6 \\
\hline \multicolumn{8}{|l|}{ Coating C } \\
\hline Heartwood & 10 & $359(44)$ & 305 & 419 & $5.5(2.7)$ & 3 & 10 \\
\hline Sapwood & 10 & $442(75)$ & 320 & 539 & $3.7(2.4)$ & 1 & 5 \\
\hline
\end{tabular}

$A$ white alkyd coating, $B$ white acrylic coating, and $C$ red acrylic coating

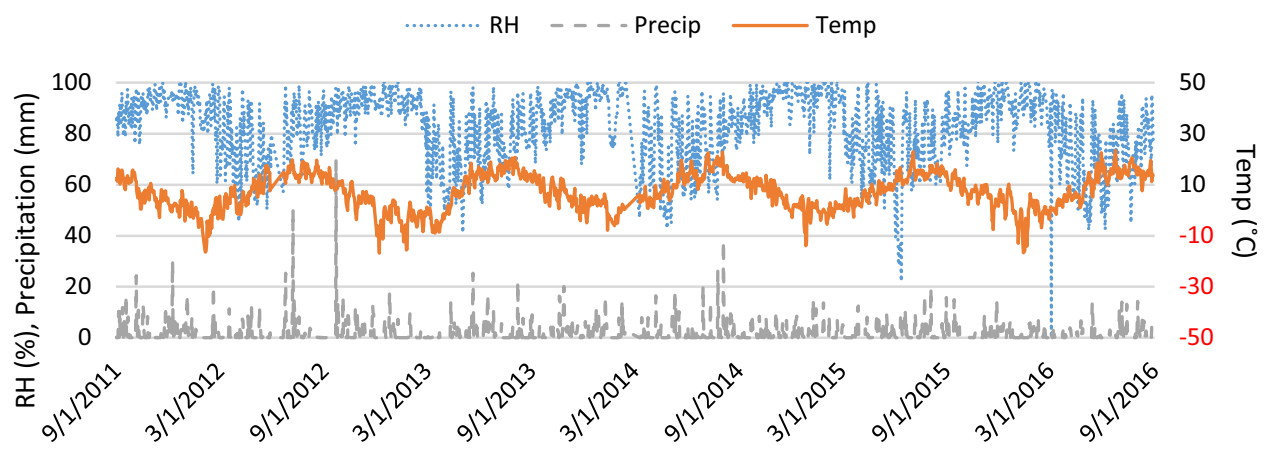

Fig. 1: Variation in temperature, relative humidity (RH), and precipitation covering the test period October 12, 2011-August 26, 2016, at Asa test field

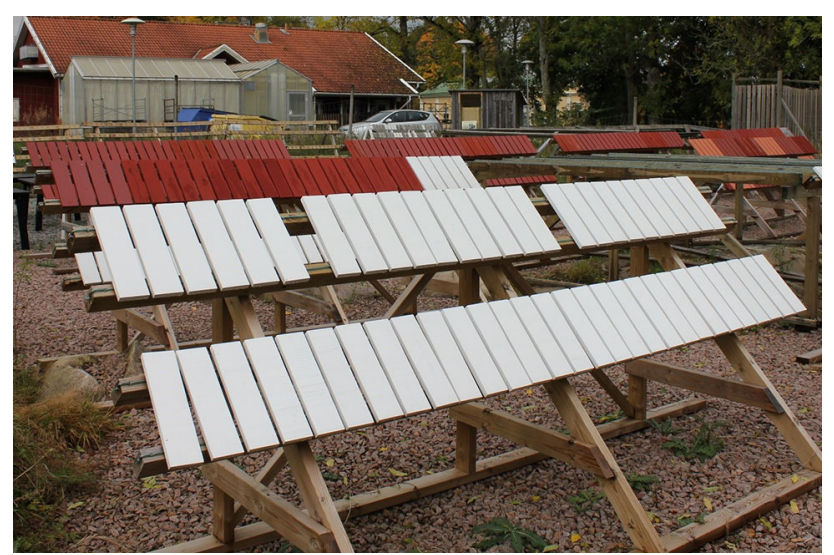

Fig. 2: Exposure racks for samples at test field

$\mathrm{MC}_{\text {average }}=\left(\sum_{1}^{n} \mathrm{MC}_{n}\right) / n$.

An independent t-test was used to analyze the significance in the level of the discoloration between heartwood and sapwood for each coating.

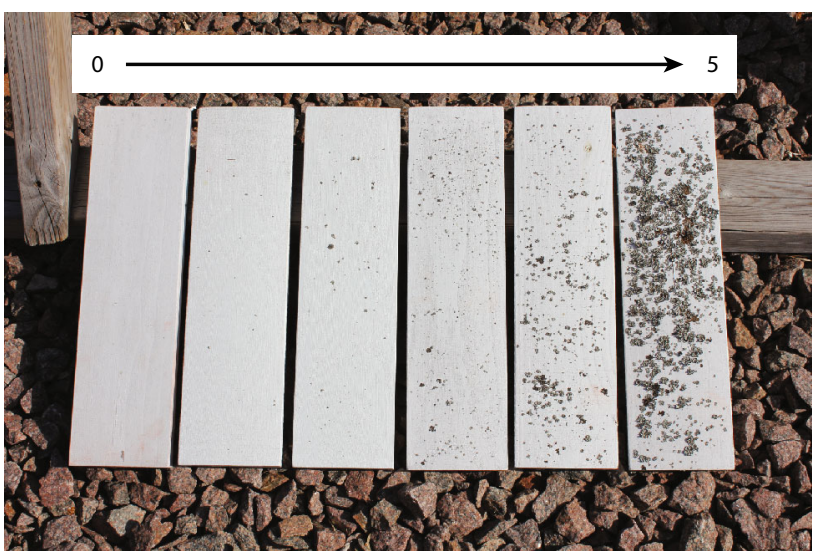

Fig. 3: Grading scale of biological growth. Grade $0=$ no detectable defects/biological growth. Grade $5=$ dense pattern of defects/biological growth

\section{Results and discussion}

Starting with the results of microorganisms growing on the surface, the samples were inspected annually, but it was only in the third year that any visible signs of colonization appeared. Table 2 presents the observed values of $\mathrm{MC}$ and growth of microorganisms. From the 
Table 2: Measured MC and biological growth during the test period (October 12, 2011-August 26, 2016) with the standard deviation given in parentheses

\begin{tabular}{|c|c|c|c|c|c|c|}
\hline \multirow[t]{2}{*}{ Sample } & \multicolumn{3}{|c|}{ MC (\%) } & \multicolumn{3}{|c|}{ Biological growth } \\
\hline & $\mathrm{MC}_{\text {average }}$ & Min & Max & June 2014 & June 2015 & June 2016 \\
\hline \multicolumn{7}{|l|}{ Coating A } \\
\hline Heartwood & $20.6(5.7)$ & 11.3 & 29.4 & $2.1(0.3)$ & $2.2(0.4)$ & $3.2(0.4)^{\circ}$ \\
\hline Sapwood & $24.9(7.4)^{*}$ & 13.7 & 39.2 & $1.6(0.5)$ & $2.0(0.9)$ & $4.3(0.7)^{\circ}$ \\
\hline \multicolumn{7}{|l|}{ Coating B } \\
\hline Heartwood & $20.4(5.9)$ & 11.4 & 29.3 & $1.0(0)$ & $1.0(0)$ & $1.5(0.5)$ \\
\hline Sapwood & $23.3(7.1)$ & 12.7 & 34.9 & $1.0(0)$ & $1.0(0)$ & $1.6(0.5)$ \\
\hline \multicolumn{7}{|l|}{ Coating C } \\
\hline Heartwood & $17.5(7.5)^{*}$ & 7.3 & 29.2 & 0 & 0 & 0 \\
\hline Sapwood & $19.7(7.6)$ & 9.2 & 32.5 & 0 & 0 & 0 \\
\hline
\end{tabular}

$A$ white alkyd coating, $B$ white acrylic coating, and $C$ red acrylic coating

Significant difference in values between the two groups, $p \leq 0.05,{ }^{*}=\mathrm{MC},{ }^{\circ}=$ biological growth
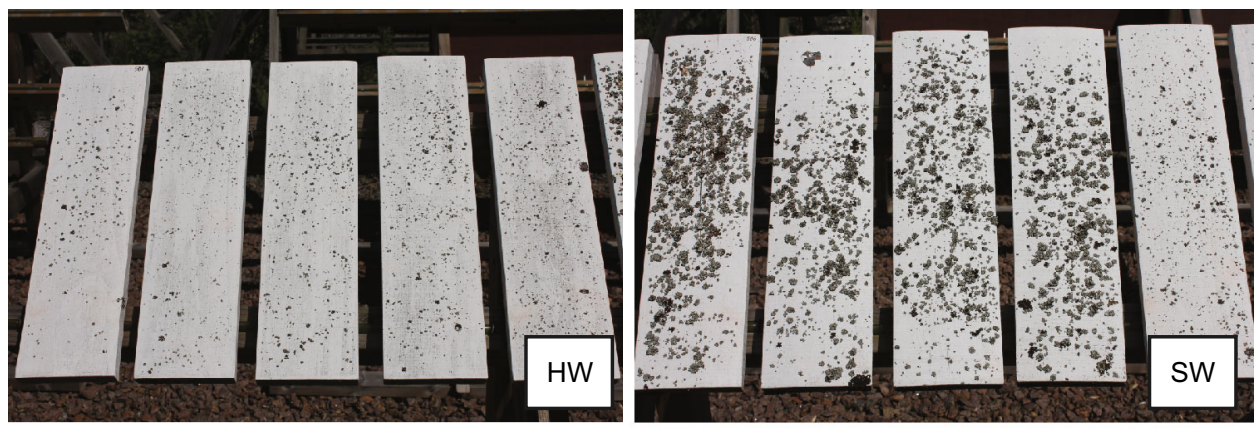

Fig. 4: A representative selection of biological growth on samples with coating A, an alkyd system. Pictures taken June 2016. HW heartwood, SW sapwood

first sign of biological growth, Sample A exhibited higher values than the samples with other coatings. Figure 4 presents a representative selection of colonized heartwood and sapwood samples with coating A. Sample A presented significantly different final biological growth values in the independent t-test performed for heartwood and sapwood spruce (Fig. 5). Gobakken et al. ${ }^{21}$ saw a greater extent of surface mold and staining fungi on the outer boards of coated spruce compared to the inner boards. It is likely that sapwood dominated Gobakken's outer boards, and if so, the results of the present study aligned with her findings. The higher degree of biological growth could also be due to a higher amount of carbohydrates (sugar) in the sapwood. The chemical compositions of heartwood and sapwood spruce extractives are quite similar except for a higher amount of triglycerides and carbohydrates (i.e., sugar) in sapwood. ${ }^{22}$ This study did not quantify the extractive contents and variations between individual heartwood or sapwood replicates. The contents and variations might have affected the results. Extractive evaluations would be very interesting in further studies on biological growth of coated wood surfaces.
Sample B resulted in a similar growth of microorganisms on the surface irrespective of the wood substrate (Fig. 5). The different behaviors exhibited through biological growth between coatings $\mathrm{A}$ and $\mathrm{B}$ confirm the importance of considering a coating formula as an experiment parameter ${ }^{23}$ since the coating itself may have an impact on biological growth of the surface. A comparison of the MC across different coatings needs proper evaluation with the coating properties in mind. The aim of this study was, however, to study the influence of wood characteristics on the $\mathrm{MC}$ and growth of microorganisms, so comparison was always done within each coating system. This study did not identify specific microorganism species, so observations concerning the behavior of specific molds, fungi, or algae cannot be made. Sample C, the redcolored coating, had no signs of microorganisms on the surface unlike the white-colored samples with the same coating formula (Sample B). The difference in red- and white-colored samples indicated an effect of color on the surface growth of microorganisms. The correlation between coating color and MC will be discussed later in the text. 


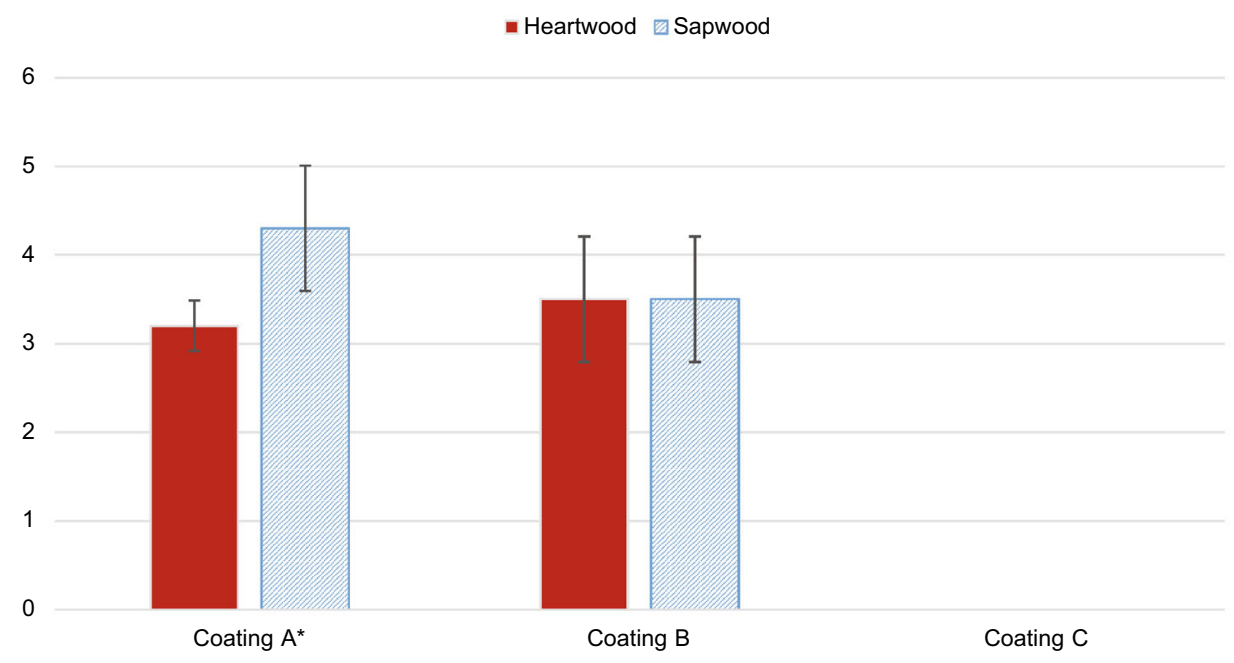

Fig. 5: Final level of biological growth after approx. 5 years of field exposure (measured in June 2016). The grading scale of growth begins at grade $0=$ no detectable growth and continues up to grade $5=$ dense pattern of growth. $A$ white alkyd coating, $B$ white acrylic coating, and $C$ red acrylic coating. *Significantly different values between heartwood and sapwood, statistical limit $\boldsymbol{p} \leq \mathbf{0 . 0 5}$

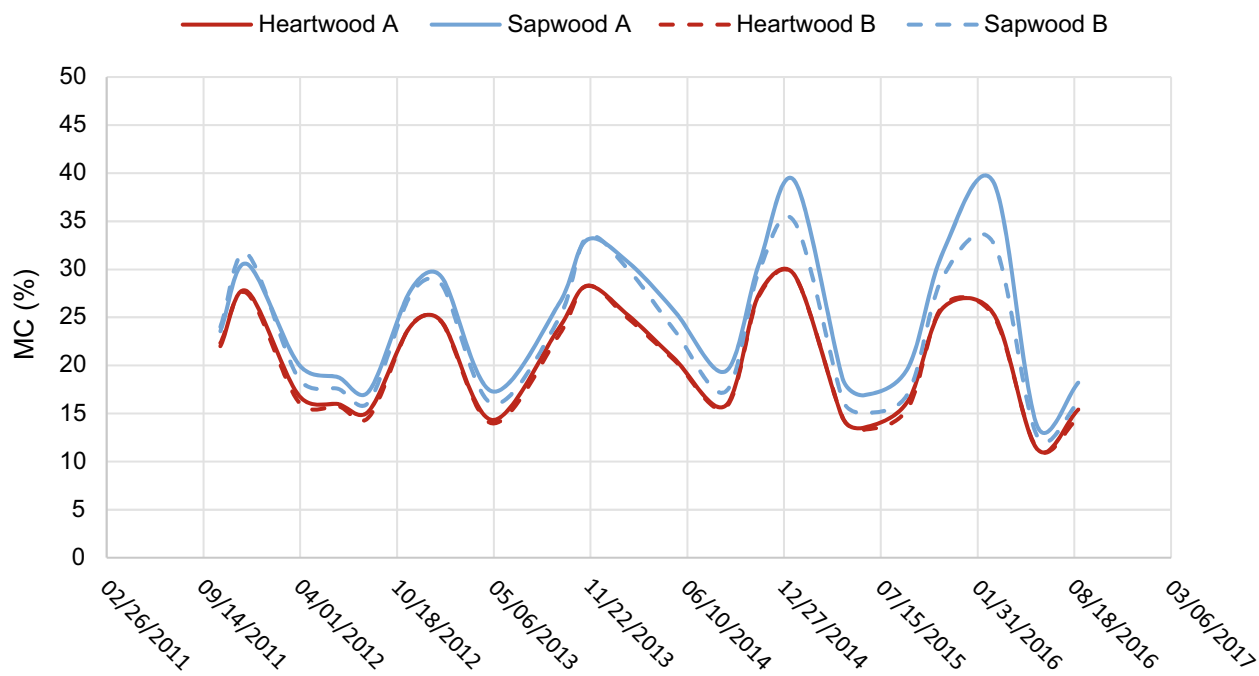

Fig. 6: Moisture fluctuation during the test period (October 12, 2011-August 26, 2016). $A$ alkyd coating, $B$ acrylic coating. The value represents the average of the ten replicates of each group

Moving to the $\mathrm{MC}$ variations of the samples, Table 2 presents the $\mathrm{MC}_{\text {average }}$ with maximum and minimum values during the test period. In general, the sapwood samples had a higher $\mathrm{MC}_{\text {average }}$ than the heartwood samples. Furthermore, the differences in MC between heartwood (HW) and sapwood (SW) were more pronounced at the maximum $\mathrm{MC}$ than at the minimum MC (coating A: $\mathrm{HW}_{\text {Max }}=29.4 \%, \mathrm{SW}_{\text {Max }}=39.2 \%$ ). It appears that the properties of sapwood spruce enhance water uptake but not its release. Surface-active extractives in sapwood have previously been suggested as a cause for enhanced water absorption in uncoated spruce samples. ${ }^{15}$ Reduced surface tension is believed to be the mechanism behind higher liquid absorption.
However, it is unlikely that the main water uptake in this study was capillary driven since a coating acted as a water barrier. The uncoated backside of the boards might, however, have influenced the results since water absorption could have taken place on the uncoated backside. Although the $45^{\circ}$ inclination of the boards limited most of the direct water exposure, the humid weather (Fig. 1) might have caused water condensation on the surface of the samples.

Figure 6 clearly illustrates the fluctuations in MC (Samples A and B). As one can see in the figure, the sapwood samples had a higher MC (an average of 10 replicates) compared to heartwood samples during the test period. These results showed that coated spruce 


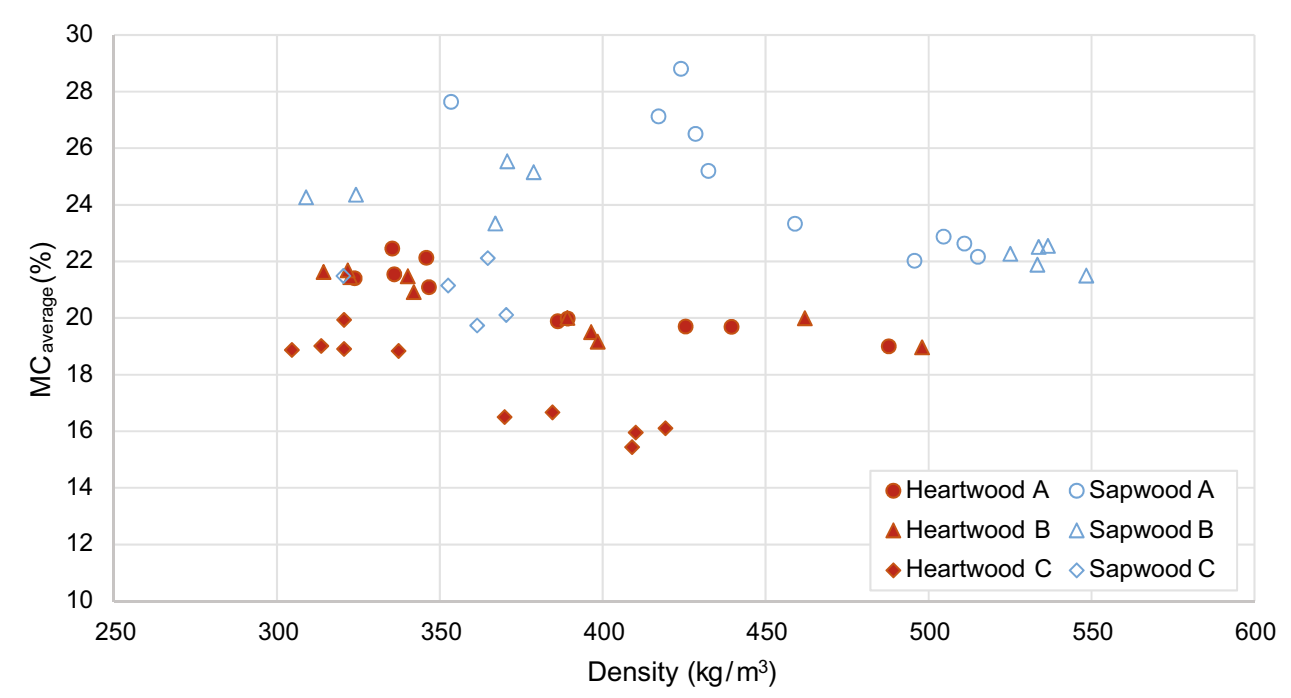

Fig. 7: $M C_{\text {average }}$ of individual replicates during the test period (October 12, 2011-August 26, 2016). $A$ white alkyd coating, $B$ white acrylic coating, and $C$ red acrylic coating

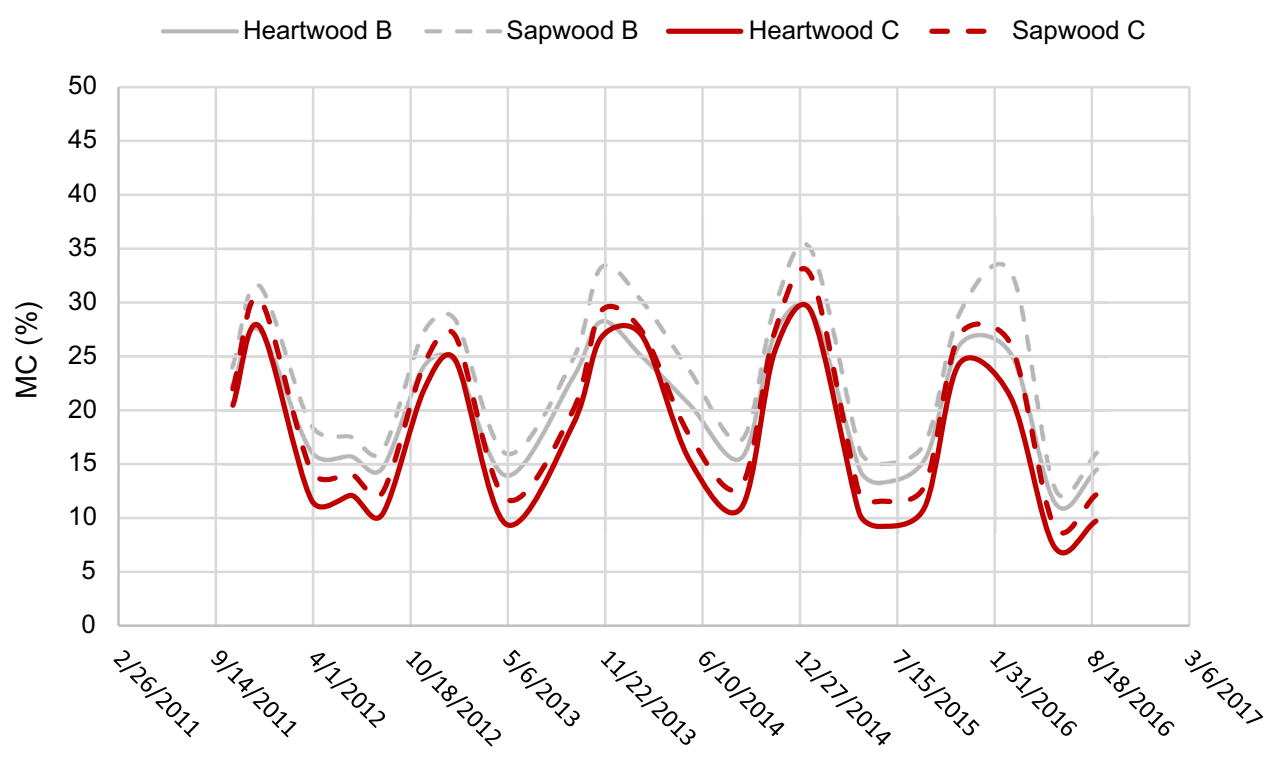

Fig. 8: MC fluctuation during the test period (October 12, 2011-August 26, 2016) comparing the same coating formula with white or red pigmentation. $B$ white acrylic coating, $C$ red acrylic coating. The value represents the average of the ten replicates of each group

samples had similar sorption behavior as uncoated spruce samples ${ }^{14,24}$ with higher water absorption in sapwood substrates than in heartwood substrates. One could also see a slightly increased gap in MC between heartwood and sapwood with prolonged exposure (winter 2014-15 and forward) in Fig. 6. The increased gap in $\mathrm{MC}$ might be due to an aging of the coating in combination with different dimensional movements of heartwood and sapwood, i.e., swelling and shrinking. More studies are, however, needed to confirm such a relationship. The presented MC was the average of the whole board and as such does not represent the local $\mathrm{MC}$ close to the coating. It can be assumed that the MC at the outer region of the board experienced far larger variations and with that larger moisture movements.

No statistically significant difference $(p \leq 0.05)$ was seen in the deeper one-way ANOVA on the $\mathrm{MC}_{\text {average }}$ of the samples, comparing heartwood and sapwood within each coating system. The only significant difference was between sapwoods with coating A and heartwoods with coating $\mathrm{C}$ (see Table 2). That significant difference was of less relevance since the samples were coated with different coatings and related to different coating properties and hence not comparable. The wide range of wood densities and the use of $\mathrm{MC}_{\text {average }}$ in the analysis could have contributed to the 
large deviation within each group, causing no significant differences in the MC levels between the other samples. However, a clear trend of a higher $\mathrm{MC}_{\text {average }}$ for sapwood samples is shown in Fig. 7 despite the insignificant differences in the ANOVA. The higher $\mathrm{MC}_{\text {average }}$ for sapwood samples was present within the entire range of studied densities. The coating permeability does inevitably affect the MC of the samples, but a comparison between the samples with the same coating is still possible.

Sample C with a red-colored coating had a lower $\mathrm{MC}_{\text {average }}$ as compared to the corresponding groups with a white color, i.e., Sample B (see Table 2). Moreover, the minimum MC was lower for the redcolored samples than for the white ones. The red color absorbs more energy from the sunlight than the white color, which is believed to expedite the drying process of the boards, especially near the surface. The assumed increased temperature of the red coatings also causes a lowered equilibrium moisture content and most likely lower MC. Figure 8 illustrates the greater ability of the red-colored samples to reach a lower MC profile than the white-colored samples.

Summarizing the results, heartwood samples with coating A had a lower level of MC and a lower level of microorganisms on the surface than the corresponding sapwood samples. The connection between the MC in the wood and the growth of microorganisms on the surface was further emphasized by the absence of microorganisms on the red-colored Samples C. Samples $\mathrm{C}$ and $\mathrm{B}$ had the same coating formula, but the red-colored Samples $\mathrm{C}$ had in contrast to the whitecolored Samples B, lower levels of MC and no growth of microorganisms on the coated surface.

\section{Conclusions}

Coated heartwood Norway spruce samples showed a clear trend with lower MC than coated sapwood Norway spruce samples. The connection was valid within each coating formula. The lower MC was, however, not statistically significant for any of the coatings, probably caused by the wide range of wood density and the use of $\mathrm{MC}_{\text {average }}$ in the analysis. The lower MC of heartwood samples also correlated with less growth of microorganisms on the surface. Heartwood samples with an alkyd coating (A) had both a lower level of MC and a significantly lower growth of microorganisms than samples made of sapwood. A similar trend in biological growth was absent on samples with an acrylic coating (B), but that could be related to the different coating formula. The importance of a low MC for less biological growth was further emphasized by the lack of microorganisms on the red-colored acrylic samples (C). The light absorbing red color in Sample C resulted in lowered MC and less growth of microorganism on the surface, as compared to the white-colored Samples B with the same coating formula. The growth of microorganisms on coated wood is, however, a multifaceted behavior and might be affected by additional parameters that were not studied in this work, such as the amount and type of extractive content.

Acknowledgments This research was performed within the Bridge, a multidisciplinary research and education collaboration between Linnaeus University and IKEA. Additionally, funding for the field experiments was provided by the Swedish Paint and Lacquer Foundation and by the Arvid Lindgrens Foundation. This study has also been made possible thanks to practical assistance from Jonaz Nilsson and the Swedish Infrastructure of Ecosystem Science (SITES), who provided us with access to the Asa field research station.

Open Access This article is distributed under the terms of the Creative Commons Attribution 4.0 International License (http://creativecommons.org/lice nses/by/4.0/), which permits unrestricted use, distribution, and reproduction in any medium, provided you give appropriate credit to the original author(s) and the source, provide a link to the Creative Commons license, and indicate if changes were made.

\section{References}

1. Gaylarde, CC, Gaylarde, PM, "A Comparative Study of the Major Microbial Biomass of Biofilms on Exteriors of Buildings in Europe and Latin America." Int. Biodeterior. Biodegrad., 55 (2) 131-139 (2005)

2. Eaton, RA, Hale, MDC, Wood: Decay, Pests, and Protection. Chapman \& Hall, London (1993)

3. Ahola, P, "Moisture Transport in Wood Coated with Joinery Paints." Eur. J. Wood Wood Prod., 49 (11) 428-432 (1991)

4. De Meijer, M, Militz, H, "Moisture Transport in Coated Wood. Part 2: Influence of Coating Type, Film Thickness, Wood Species, Temperature and Moisture Gradient on Kinetics of Sorption and Dimensional Change." Eur. J. Wood Wood Prod./Holz als Roh- und Werkstoff, 58 (6) 467475 (2001)

5. Donkers, PAJ, Huinink, HP, Erich, SJF, Reuvers, NJW, Adan, OCG, "Water Permeability of Pigmented Waterborne Coatings." Progr. Org. Coat., 76 (1) 60-69 (2013)

6. Grüll, G, Truskaller, M, "Moisture Protection of Wood Coatings and Its Sensitivity to Mechanical Defects Depending on Surface Hydrophobicity and Solid Content." Int. Wood Prod. J., 5 (2) 74-82 (2014)

7. Gobakken, LR, Westin, M, "Surface Mould Growth on Five Modified Wood Substrates Coated with Three Different Coating Systems When Exposed Outdoors." Int. Biodeterior. Biodegrad., 62 (4) 397-402 (2008)

8. Sandberg, K, "Degradation of Norway Spruce (Picea abies) Heartwood and Sapwood During 5.5 Years' Above-Ground Exposure." Wood Mater. Sci. Eng., 3 (3) 83-93 (2008)

9. Sivertsen, MS, Flæte, PO, "Water Absorption in Coated Norway Spruce (Picea abies) Cladding Boards." Eur. J. Wood Wood Prod., 70 (1-3) 307-317 (2012) 
10. Blom, ̊̊, Johansson, J, Sivrikaya, H, "Some Factors Influencing Susceptibility to Discoloring Fungi and Water Uptake of Scots Pine (Pinus sylvestris), Norway Spruce (Picea abies) and Oriental Spruce (Picea orientalis)." Wood Mater. Sci. Eng., 8 (2) 139 (2013)

11. Altgen, M, Militz, H, "Thermally Modified Scots Pine and Norway Spruce Wood as Substrate for Coating Systems." $J$. Coat. Technol. Res., 14 (3) 531-541 (2017)

12. Hillis, WE, Heartwood and Tree Exudates. Springer, Berlin (1987)

13. Metsä-Kortelainen, S, Antikainen, T, Viitaniemi, P, “The Water Absorption of Sapwood and Heartwood of Scots Pine and Norway Spruce Heat-Treated at $170{ }^{\circ} \mathrm{C}, 190^{\circ} \mathrm{C}, 210^{\circ} \mathrm{C}$ and $230^{\circ}$ C." Eur. J. Wood Wood Prod., 64 (3) 192-197 (2006)

14. Sandberg, K, Salin, J-G, "Liquid Water Absorption in Dried Norway Spruce Timber Measured with CT Scanning and Viewed as a Percolation Process." Wood Sci. Technol., 46 (1) 207-219 (2012)

15. Sjökvist, T, Wålinder, MEP, Blom, ̊̊, "Liquid Sorption Characterisation of Norway Spruce Heartwood and Sapwood Using a Multicycle Wilhelmy Plate Method." Int. Wood Prod. J., 9 (2) 58-65 (2018)

16. Lie, SK, Vest $\varnothing l$, GI, Høibø, O, Gobakken, LR, "Surface Mould Growth on Wooden Claddings-Effects of Transient Wetting, Relative Humidity, Temperature and Material Properties." Wood Mater. Sci. Eng., (2018). https://doi.org/ 10.1080/17480272.2018.1424239

17. Williams, RS, Jourdain, C, Daisey, GI, Springate, RW, "Wood Properties Affecting Finish Service Life." J. Coat. Technol., 72 (902) 35-42 (2000)
18. Kühne, H, Leukens, U, Sell, J, Wälchli, O, "Untersuchungen an bewitterten Holzoberflächen-Erste Mitteilung: Rasterelektronenmikroskopische Beobachtungen an Vergrauungspilzen." Holz als Roh- und Werkstoff, 28 (6) 223-229 (1970)

19. Grüll, G, Truskaller, M, Podgorski, L, Bollmus, S, De Windt, I, Suttie, E, "Moisture Conditions in Coated Wood Panels During 24 Months Natural Weathering at Five Sites in Europe." Wood Mater. Sci. Eng., 8 (2) 95-110 (2013)

20. CEN, EN ISO 4628-1:2003 Paints and Varnishes-Evaluation of Degradation of Coatings-Designation of Quantity and Size of Defects, and of Intensity of Uniform Changes in Appearance-Part 1: General Introduction and Designation System. European Committee for Standardization (2003)

21. Gobakken, LR, Vestøl, GI, Sivertsen, MS. "Effects of Wood Properties on Surface Mould Growth on Coated Claddings of Norway Spruce." Proceedings of the 7th Meeting of the Nordic-Baltic Network in Wood Material Science and Engineering (WSE), 2011

22. Ekman, R, "Analysis of the Nonvolatile Extractives in Norway Spruce Sapwood and Heartwood." Acta Acad. Abo., 39 (4) 1-20 (1979)

23. Gobakken, LR, Lebow, PK, "Modelling Mould Growth on Coated Modified and Unmodified Wood Substrates Exposed Outdoors." Wood Sci. Technol., 44 (2) 315-333 (2010)

24. Bergström, M, Blom, А. "Differences in Properties Between Norway Spruce (Picea abies) Heartwood and Sapwood. Part 2. Vapour and Liquid Permeability." Wood Protection Conference, New Orleans, USA 2006 